\title{
The Association Between Sociodemographic, Clinical Factors, Hand-grip Strength, and Erectile Dysfunction Among Men With Metabolic Syndrome Attending a Primary Care Clinic
}

Nik Aminah Nik Abdul Kadir

Universiti Teknologi MARA

Suraya Abdul-Razak ( $\sim$ suraya617@uitm.edu.my )

Universiti Teknologi MARA

Aqil M. Daher

International Medical University

Nafiza Mat-Nasir

Universiti Teknologi MARA

\section{Research Article}

Keywords: erectile dysfunction (ED), Metabolic Syndrome (MetS), hand-grip strength (HGS), muscle strength, Malaysia, primary care

Posted Date: February 3rd, 2022

DOI: https://doi.org/10.21203/rs.3.rs-1310841/v1

License: (9) This work is licensed under a Creative Commons Attribution 4.0 International License.

Read Full License 


\section{Abstract}

Introduction: Erectile dysfunction (ED) is a serious health problem and an independent predictor for cardiovascular diseases (CVD). The prevalence increases with age, but little is known about the relationship between physical fitness and ED especially among men with high risk of CVD. Hence, this study aimed to determine the prevalence of ED among men with Metabolic Syndrome (MetS) and its association with hand-grip strength in which is a measurement of physical fitness and muscle strength.

Methods: A cross-sectional study was conducted among Malaysian men aged $\geq 40$ years who had their follow-up between $1^{\text {st }}$ June 2021 and $30^{\text {th }}$ October 2021 at an institutional primary care clinic in Gombak district, Selangor, Malaysia. The participants were recruited via computer generated simple random sampling. Data on sociodemographic, comorbidities, anthropometry, clinical examinations including hand-grip strength (HGS) and blood chemical profiles were collected. While a validated English and Malay versions of the 5-item International Index of Erectile Function (IIEF-5) were used to assess presence of ED. Multiple logistic regression analysis were conducted to determine the association between sociodemographic, comorbidities, blood chemical profiles, and HGS with ED.

Results: There were 334 participants recruited in the study. The mean age was $58.8( \pm 8.84)$ years old, with majority were Malays $(95.2 \%, n=318)$ and married $(98.8 \%, n=330)$. The overall prevalence of selfreported ED was $79 \%$ (95\% confidence interval [CI]: 0.75-0.84). Multivariable analysis showed that ED was associated with elderly aged $\geq 60$ years (odds ratio [OR] 3.27, 95\% Cl: $1.60-6.69$ ), HGS (OR 15.34, 95\% Cl: 5.64-41.81) and abnormal total cholesterol (OR 0.36, 95\% Cl: 0.16-0.78).

Conclusion: ED was highly prevalent among Malaysian men aged $\geq 40$ years with MetS. Being older than 60 years of age and low HGS are associated with higher risk of ED. Robust screening of ED among men with Mets and intervention to improve muscle strength and physical fitness may be warranted.

\section{Introduction}

Erectile dysfunction (ED) is a global health problem that affects nearly half of men over the age of 40 years (1-4). In Malaysia, more than two third of men aged above 40 years have ED (5), while a majority of elderly Malaysians aged above 65 years old had ED in 2014 (6). ED is known to be attributed by various pathological mechanisms such as vascular impairment, neurological, hormonal, and psychological components with the most prevalent cause of ED is vascular ED, for which accounted for up to $70 \%$ of all cases (7). Robust studies had proven that ED has positive association with hypertension, dyslipidemia, diabetes mellitus, heart disease, smoking, excessive alcohol use, obesity, depression, and metabolic syndrome (MetS) (8). ED is also an independent predictor of occult coronary artery disease (9).

Being physically active has been documented to reduce the risk of non-communicable diseases (10), the likelihood of major cardiovascular diseases (CVD) (11), improves quality of life (10) and is associated with better erectile function (12). Physical inactivity is a recognised risk factor for CVD (13) and an emerging risk factor in the development of ED (12). The majority of evidences suggested that aerobic 
exercises has beneficial effects on CVD risks and continue to be the most common exercise prescription (11). On the other hand, resistance training exercises have different physiologic effects, that it improves muscle strength and appears to have positive effects on chronic heart failure (14), frailty (15), osteoporosis (16), and CVD risks (17).

Muscle strength is expressed as musculoskeletal fitness, which is an integral part of physical fitness(18). Musculoskeletal fitness is a complex concept which refers to ability of a specific muscles group to generate force (i.e. muscular strength), to resist repeated contractions over time (i.e. muscular endurance), and to exert force per unit of time (i.e. muscular power) (18). Muscle strength can be measured in a variety of ways including isometric muscle strength e.g. the hand-grip strength (HGS), knee extension and flexion (19). Meanwhile, cardiorespiratory fitness is another component of physical fitness which also has been linked to the prevention of CVD and CVD risks (20) and is commonly measured using maximal oxygen uptake.

HGS is widely used and known potential indicator of health conditions and a reliable measurement using a dynamometer where a person applies maximal isometric hand grip force for a short duration (21). Low HGS has been associated with higher all-cause cardiovascular and non-cardiovascular mortality $(16,21)$, frailty in the elderly (22), chronic obstructive airway diseases, spine-related problems (23) and ED (24). Data are scarce but a higher HGS also predicted a lower risk of ED among elderly men aged above 50 years (24), and improved erectile function by $16 \%$ (25). While a better HGS has been associated with younger age (26), being male (26), normal body mass index, non-smoker or does not consume any alcohol (27) and being physically active (28).

Muscle mass and strength begins to decline in the fourth decade of life and accelerates around the age of 40 years and older. Given the necessity of maintaining muscle strength for optimal health, it is crucial to understand how muscle strength associated with ED among men over the age of 40 years. Hence this study aimed to determine the association between HGS and ED as well as prevalence of ED in men with MetS and other associated factors, including sociodemographic and clinical factors.

\section{Material And Methods}

\section{Study design and setting}

A cross sectional study was conducted between June 2021 and October 2021 at an institutional primary care specialist clinic located in Gombak district Selangor, Malaysia. This clinic located at an urban area which covers an area of $839.1 \mathrm{~km}^{2}$ with a dense total population of 629,971 (29). The services provided include chronic diseases, acute care, adolescent clinic, and health screenings by a multi-disciplinary team consisted of family physicians, registrar of family medicine postgraduate programme, nurses, pharmacists, dieticians, and administrative staffs. The clinic also served as a teaching clinic for the medical undergraduates.

\section{Participants and Sampling}


Adult male patients who had their follow-up between 1st June 2021 and 30th October 2021 were eligible to participate in the study. The inclusion criteria were: men aged $\geq 40$ years, diagnosed to have MetS by the Joint Interim Statement (JIS) criteria (30) (see box 1), able to read and understand Malay or English language, and had blood tests (fasting plasma glucose, fasting serum lipid, and HbA1c) at least 6 months prior the conduct of the study. Sampling was done via computer generated simple random sampling method.

Box 1: Diagnostic criteria of Metabolic Syndrome (MetS) based on JIS 2009 criteria

MetS is diagnosed if three or more of the following five criteria were satisfied:

1. Waist circumference (WC) using South Asian cut-points: Male $\geq 90 \mathrm{~cm}$ or Female $\geq 80 \mathrm{~cm}$;

2. Systolic blood pressure (SBP) $\geq 130 \mathrm{mmHg}$ and/or diastolic blood pressure $(\mathrm{DBP}) \geq 85 \mathrm{mmHg}$ or on treatment for hypertension;

3. Fasting plasma glucose $(F P G) \geq 5.6 \mathrm{mmol} / \mathrm{L}$ or on treatment for elevated glucose;

4. Triglyceride (TG) $\geq 1.7 \mathrm{mmol} / \mathrm{L}$ or on treatment for $\mathrm{TG}$;

5. High Density Lipid-Cholesterol (HDL): Male $<1.0 \mathrm{mmol} / \mathrm{L}$ or female $<1.3$

The exclusion criteria were: (i) established diagnosis of psychiatry illness or were mentally challenged (e.g., depression and anxiety disorder); (ii) presence of residual weakness from stroke (e.g., unilateral weakness, pure motor stroke, and sensory-motor stroke); (iii) past history of surgical treatment for ED (e.g., penile prostheses); (iv) patients who received hormone therapy for ED (e.g., testosterone therapy); (v) patients who were on anti-hypertensives (e.g., thiazide diuretics and beta blocker), antidepressants (e.g., selective serotonin reuptake inhibitors and tricyclics), antipsychotics (e.g., neuroleptics), and antiandrogens (e.g., GnRH analogues and antagonists); (vi) current injury or history of wrist and hand injury in the past 1 month; (vii) history of wrist and hand surgery in the past 3 months.

The sample size was calculated using single proportion formula based on the objective of the study. According to Abdul Rahman et al, the prevalence of ED among adult males aged 40-76 years old was $69.5 \%$. (5) Taking the alpha value of 0.05 with confidence interval of $95 \%$, the minimum required sample was 304 patients. Considering a 15\% non-response rate, the final sample was 350 participants.

\section{Study instruments}

A four-part questionnaire was devised for data collection. The sociodemographic and medical history section was constructed to obtain information of participant's age, ethnicity, education level, marital status, household income, smoking and alcohol status and comorbid history. Clinical examinations such as weight, height, body mass index (BMI), waist circumference (WC), blood pressure (BP), and HGS were performed and documented. The blood profile results including fasting plasma glucose, fasting serum 
Lipid, and $\mathrm{HbA1c}$ were obtained from electronic medical record (EMR) and International Index of Erection -5 (IIEF-5) was used to measure ED.

HGS was determined using a Jamar dynamometer (Sammons Preston, Bolingbrook, IL, USA) according to a standardised protocol (31). The arm was positioned vertically to the body with the elbow flexed to $90^{\circ}$ while holding the dynamometer. The participant was instructed to squeeze the device as hard as possible for three seconds. The measurement was repeated thrice at 30 second intervals. Each participant's dominant hand was measured three times. In this study, the highest measurement obtained for the dominant hand was used (26). The reference range of HGS was developed in a large epidemiological study in United Kingdom in 2014 involving 60,803 respondents, including 49,964 male participants and 26,687 female participants from 12 general population studies in Great Britain, where centile curves were produced based on age for ages 4 to 90 years (26). The result of HGS within each stratum was displayed in centile, stratified according to age and gender.

The IIEF-5 questionnaire was bilingual with both English and Malay. Lim et al. adapted and validated the Malay version of the IIEF-5 in 2003 (32). The sensitivity and specificity of the IIEF-5 questionnaire were $85 \%$ and $75 \%$, respectively, with a Cronbach alpha of 0.9 (32). The IIEF- 5 consisted of five items, where each item was scored on a five or six-point scale, ranging from zero to five. The total score ranged from 1 to 25. The presence of ED was indicated by IIEF-5 scores that were equal or less than 21 . The severity of ED was further categorised based on the IIEF-5 scores: severe (5-7), moderate (8-11), mild to moderate (12-16), mild (17-21), and no ED (22-25).

\section{Study variables}

The dependant variable for the study was presence of ED as diagnosed using the IIEF-5 questionnaire. Age, ethnicity, marital status, household income, education level, smoking, alcohol intake, presence of comorbidity, waist circumference (WC), obesity, HSG, and blood profiles were the independent variables. Malay or non-Malay ethnicities were distinguished. Marital status was grouped as either married or single/divorced/widowed. Meanwhile, household income was divided into i) high (T20) and middle income (M40) if $\geq$ RM4,850/household; or ii) low income (B40) if < RM4,850/household. These classification were developed in 2019 according to the Household Income and Basic Amenities Survey Report, 2019 (33). While education level was categorised into; i) secondary and below; or ii) tertiary. Secondary and below education level is defined as either having no formal education or has attended primary and/or secondary school from the age of seven years up to 17 years old. Meanwhile, tertiary education is defined as any education pursued beyond secondary school including universities and colleges. Regarding alcohol consumption, alcohol drinker are defined as those who drink alcohol daily, weekly or occasionally for the past 12 months in the past one year (34). Non-drinker is defined as those who did not drink any alcohol in the past one year. For smoking status, participants were classified as ever smoked if they were currently smoking or an ex-smoker who had at least stopped smoking in the past 30 days. Whereas, never smoked is defined as those who had never smoked in the past. Hypertension, diabetes mellitus (DM), and coronary artery disease, cerebrovascular accidents were present if these diagnoses were recorded in the EMR, or participants were on medication for these 
conditions. Dyslipidemia was identified via patient self-report of diagnosis of 'high cholesterol', cholesterol-lowering medication taken, or any elevation of fasting serum lipid. The definition of elevation of fasting serum lipid were as follows: Total cholesterol (TC) $>5.2 \mathrm{mmol} / \mathrm{L}$, high density lipoprotein cholesterol (HDL-C) $<1.0 \mathrm{mmol} / \mathrm{L}$ (males) or $<1.2 \mathrm{mmol} / \mathrm{L}$ (females), Triglycerides (TG) $>1.7 \mathrm{mmol} / \mathrm{L}$, and elevated low density lipoprotein - cholesterol (LDL-C) levels (35). The LDL-C levels will depend on the patient's cardiovascular risk. (35). (See box 2).

Box 2: Risk Stratification of Cardiovascular (CV) Risk and Target LDL-C Levels.

1. Low CV risk $<3 \mathrm{mmol} / \mathrm{L}$

- FRS (Framingham Risk Score) 10- year CVD Risk $<10 \%$

2. Intermediate (Moderate) $\mathrm{CV}$ risk $<3 \mathrm{mmol} / \mathrm{L}$

- FRS 10- year CVD Risk 10\% - 20\%

3. High CV risk $\leq 2.6 \mathrm{mmol} / \mathrm{L}$

- diabetes without target organ damage

- CKD with eGFR $\geq 30-6030 \mathrm{ml} / \mathrm{min}$ - $1 / 1.73 \mathrm{~m}^{2}$ (stage 3 )

- FRS 10- year CVD Risk $>20 \%$

4. Very high $\mathrm{CV}$ risk $<1.8 \mathrm{mmol} / \mathrm{L}$

- Established CVD

- Diabetes with proteinuria

- chronic kidney disease with eGFR $<30 \mathrm{ml} / \mathrm{min}-1 / 1.73 \mathrm{~m}^{2}$ (stage 4)

* eGFR (estimated glomerular filtration rate)

Weight and height were measured using Secca 767 and were expressed as kilogram $(\mathrm{kg})$ and centimeter $(\mathrm{cm})$ respectively. WC was measured to the nearest $0.1 \mathrm{~cm}$ by using non-stretchable measuring tape with the participants standing in a relaxed position and arms at the side. The measurement was taken at the midpoint between the lower rib margin (12th rib) and the iliac crest. Obesity was defined as BMI $\geq 27.5$ $\mathrm{kg} / \mathrm{m} 2$ (36).

\section{Data Collection}

This study employed a simple random sampling method. A list of all male patients who had their followup between 1/1/2020 and 31/12/2020 at the clinic were obtained from the IT Unit. All male patients who were classified as MetS based on the JIS criteria were randomly sampled using a computer-generated random sampling number. Their presence on the follow-up day was confirmed by phone call. On the patient's follow-up day, they were given the patient's information leaflet (PIL) and consent form and their eligibility according to the inclusion and exclusion criteria were done. Eligible participants who consented were given a data collection form and were examined. Data were collected by a trained research assistant to guarantee a uniform data gathering procedure. Figure 1 illustrate the flowchart for this study.

\section{Statistical analysis}


The IBM® Statistical Package for Social Sciences (SPSS) version 27 software (IBM Corp., Armonk, NY, USA) was used for data entry and statistical analysis. The sociodemographic characteristics, clinical profiles, and prevalence of erectile dysfunction among men with MetS were described using descriptive analysis. The continuous data were described either in terms of mean with standard deviations (SD) or median with interquartile ranges (IQR) based on normality of distribution. The categorical data was described using frequencies and percentages. To identify the factors associated with erectile dysfunction, inferential analysis was used. Odds ratios (OR) and their $95 \%$ confidence intervals $(\mathrm{Cl})$ were calculated using simple logistic regression (SLogR) and multiple logistic regression (MLogR). Variables with a $p$ value that was $<0.25$ from the SLogR were subsequently included in the MLogR. The MLogR was performed using the forward binary logistic regression method. Model fitness was checked using the Hosmer-Lemeshow goodness-of-fit test. Interactions, multicollinearity, and assumptions were also checked. Statistical significance was taken at a $p$-value that was $<0.05$.

\section{Result}

The sociodemographic and clinical characteristics are shown in Table 1. The mean age was $58.8( \pm 8.84)$ years old. The majority were Malays (95.2\%) and married (98.8\%). More than half of participants were non-smokers (52.4\%), and most did not consume alcohol (95.8\%). A majority had been diagnosed with hypertension and dyslipidemia, which were $76.6 \%$ and $97.9 \%$, respectively while slightly more than half had diabetes (52.4\%). 
Table 1

Sociodemographic and clinical characteristics of the participants $(n=334)$

Characteristics

Age Mean ( $( \pm S D)$ years

\section{Age groups (years) $(n, \%)$}

Young $(\geq 40$ to $<60)$

153

$(45.80)$

Elderly $(\geq 60)$

181

$(54.20)$

\section{Marital status ( $n, \%)$}

Married

Single/divorcee/ widower

$4(1.20)$

\section{Ethnicity $(n, \%)$}

Malay

Others

\section{Education level $(n, \%)$}

Secondary or below

Tertiary

Household Income (RM) (n, \%)

B40 (< RM4850 /household)

M40 and T20 ( $\geq$ RM4850 to > RM10,959/ household)

\section{Smoking status $(n, \%)$}

Non-smoker

Former smoker

Active smoker

Alcohol consumption ( $n, \%)$ 


\begin{tabular}{|c|c|}
\hline Characteristics & $n=334$ \\
\hline No & $\begin{array}{l}320 \\
(95.80)\end{array}$ \\
\hline Yes & $14(4.20)$ \\
\hline \multicolumn{2}{|l|}{ Hypertension (n, \%) } \\
\hline No & $\begin{array}{l}78 \\
(23.40)\end{array}$ \\
\hline Yes & $\begin{array}{l}256 \\
(76.60)\end{array}$ \\
\hline \multicolumn{2}{|l|}{ Diabetes Mellitus (n, \%) } \\
\hline No & $\begin{array}{l}175 \\
(52.40)\end{array}$ \\
\hline Yes & $\begin{array}{l}159 \\
(47.6)\end{array}$ \\
\hline \multicolumn{2}{|l|}{ Dyslipidaemia (n, \%) } \\
\hline No & $7(2.10)$ \\
\hline Yes & $\begin{array}{l}327 \\
(97.90)\end{array}$ \\
\hline \multicolumn{2}{|l|}{ Coronary Artery Disease (n, \%) } \\
\hline No & $\begin{array}{l}282 \\
(84.40)\end{array}$ \\
\hline Yes & $52(15.60)$ \\
\hline \multicolumn{2}{|c|}{ Cerebrovascular Accident (n, \%) } \\
\hline No & $\begin{array}{l}316 \\
(94.60)\end{array}$ \\
\hline Yes & $18(5.40)$ \\
\hline \multicolumn{2}{|l|}{ BMI $\left(k g / m^{2}\right)(n, \%)$} \\
\hline Normal ( $\geq 18.5$ to $<23$ ) & $28(8.40)$ \\
\hline Overweight ( $\geq 23$ to $<27.5$ ) & $\begin{array}{l}128 \\
(38.30)\end{array}$ \\
\hline Obesity ( $\geq 27.5$ ) & $\begin{array}{l}178 \\
(53.30)\end{array}$ \\
\hline \multicolumn{2}{|l|}{ Waist circumference $(\mathrm{n}, \%)$} \\
\hline Normal $(\mathrm{WC}<90 \mathrm{~cm})$ & $\begin{array}{l}151 \\
(45.20)\end{array}$ \\
\hline
\end{tabular}




\section{Characteristics}

$n=334$

Abnormal $(\mathrm{WC} \geq 90 \mathrm{~cm})$

\section{$\operatorname{SBP}(n, \%)$}

Normal (SBP $<140$ mmHg)

182

(54.50)

Abnormal (SBP $\geq 140 \mathrm{mmHg}$ )

\section{$\operatorname{DBP}(n, \%)$}

Normal (DBP $<90 \mathrm{mmHg}$ )

Abnormal (DBP $\geq 90 \mathrm{mmHg}$ )

\section{FBS $(n, \%)$}

Normal $(F B S<7.0 \mathrm{mmol} / \mathrm{L})$

Abnormal (FBS $\geq 7.0 \mathrm{mmol} / \mathrm{L}$

\section{$\operatorname{HbA1c}(n=167, \%)$}

Normal $(\mathrm{HbA} 1 \mathrm{c}<6.5 \mathrm{mmol} / \mathrm{L})$

Abnormal $(\mathrm{HbA} 1 \mathrm{c} \geq 6.5 \mathrm{mmol} / \mathrm{L})$

\section{Total cholesterol}

Normal (Total cholesterol $<5.2 \mathrm{mmol} / \mathrm{L}$ )

Abnormal (Total cholesterol $\geq 5.2 \mathrm{mmol} / \mathrm{L}$ )

\section{Triglyceride (n, \%)}

Normal (Triglyceride $\leq 1.7 \mathrm{mmol} / \mathrm{L}$ )

Abnormal (Triglyceride $>1.7 \mathrm{mmol} / \mathrm{L}$ )

\section{LDL (mmol/L) based on CV risk ( $\mathrm{n}, \%)$}

Normal (Very High Risk: LDL $<1.8 \mathrm{mmol} / \mathrm{L}$, High Risk: LDL $\leq 2.6 \mathrm{mmol} / \mathrm{L}$, Moderate risk and Low risk $\mathrm{LDL}<3 \mathrm{mmol} / \mathrm{L}$ ) 


\section{Characteristics}

$n=334$

Abnormal (Very High Risk: LDL $\geq 1.8 \mathrm{mmol} / \mathrm{L}$, High Risk: $\mathrm{LDL}<2.6 \mathrm{mmol} / \mathrm{L}$, Moderate risk and Low risk $\mathrm{LDL} \geq 3 \mathrm{mmol} / \mathrm{L}$ )

HDL

Normal (HDL > $1.0 \mathrm{mmol} / \mathrm{L})$

Abnormal (HDL $\leq 1.0 \mathrm{mmol} / \mathrm{L})$

Hand Grip Strength centile (kg)

$\geq 50$ th

$\geq 25$ th to $<50$ th

$\geq 10$ to $<25$ th

$<10$ th

The overall prevalence of ED was 79.6\% (95\% Cl: $0.75-0.84)$. A total of 266 participants had ED in various severities of which $45.8 \%$ of them had mild ED, more than a third of them had mild to moderate ED, while $11.3 \%$ of them had moderate ED, and another $11.3 \%$ of them had severe ED (see Table 2).

Table 2

Severity of ED among men with ED $(n=266)$

\begin{tabular}{|ll|}
\hline Severity of ED & Proportion (n, \%) \\
\hline Mild (score $\geq 17$ to $\leq 21)$ & $122(45.80)$ \\
\hline Mild to moderate $($ score $\geq 12$ to $<17)$ & $84(31.60)$ \\
\hline Moderate (score $\geq 8$ to $<12)$ & $30(11.30)$ \\
\hline Severe (score $\geq 1$ to $<8)$ & $30(11.30)$ \\
\hline
\end{tabular}

In univariate binary logistic regression, the significant factors of ED were as follows: elderly, tertiary education, income classification (middle and high income), active smoking hypertensive, obesity, abnormal blood pressure, abnormal fasting serum lipid and HGS. (see Table 3). Diabetes mellitus, coronary artery disease, and dyslipidemia did not show significant results. All variables with $p<0.25$ in the univariate analysis were included in the multivariate analysis. 
Table 3

Factors associated with ED among men with Metabolic Syndrome from simple logistic regression analysis

\section{Variable}

Wald

(df)

Crude OR

$P$-value $(95 \% \mathrm{Cl})$

\section{Age Group (years)}

Young $(\geq 40$ to $<60)$

Elderly $(\geq 60)$

$23.00(1)$

1

ref

4.26

$(2.36,7.70)$

\section{Marital Status}

Unmarried/ divorcee/ widower

Married

$\begin{array}{ll}0.00(1) & 0.000 \\ & (0.00)\end{array}$

ref

Married

\section{Ethnicity}

Malay

1

ref

Others

$0.23(1)$

0.76

$(0.24,2.42)$

$<0.001^{*}$

ref

\section{Education Level}

Low Education (no formal education/primary/secondary)

1

ref

High Education

$2.93(1)$

$0.59(0.32-$ 1.08)

0.999

0.638

\section{Household Income (RM)}

Low income (< RM4850 /household)

1 ref

Middle \& High Income ( $\geq$ RM4850 to > RM10,959/ household)

$\begin{array}{ll}4.86(1) & 0.54(0.31 \\ & -0.93)\end{array} \quad \mathbf{0 . 0 2 8 *}$

\section{Smoking status}

Nonsmoker

Former smoker

$0.01(1)$

1

ref

Active smoker

3.13(1)

$0.97(0.52-$
$1.81)$

0.914

$0.54(0.27$

$-1.07)$

\section{Alcohol Consumption}

No

ref

${ }^{\star} P$-value $<0.25$ is statistically significant. 


\begin{tabular}{|c|c|c|c|}
\hline Variable & $\begin{array}{l}\text { Wald } \\
\text { (df) }\end{array}$ & $\begin{array}{l}\text { Crude OR } \\
(95 \% \mathrm{Cl})\end{array}$ & $P$-value \\
\hline Yes & $0.01(1)$ & $\begin{array}{l}0.94(0.25- \\
3.45)\end{array}$ & 0.919 \\
\hline \multicolumn{4}{|l|}{ Hypertension } \\
\hline No & & 1 & ref \\
\hline Yes & $2.08(1)$ & $\begin{array}{l}1.59(0.85- \\
3.01)\end{array}$ & $0.150 *$ \\
\hline \multicolumn{4}{|l|}{ Diabetes Mellitus } \\
\hline No & & 1 & ref \\
\hline Yes & $0.18(1)$ & $\begin{array}{l}1.12(0.66 \\
-1.92)\end{array}$ & 0.668 \\
\hline \multicolumn{4}{|l|}{ Dyslipidemia } \\
\hline No & & 1 & ref \\
\hline Yes & $0.16(1)$ & $\begin{array}{l}0.65(0.08- \\
5.46)\end{array}$ & 0.689 \\
\hline \multicolumn{4}{|l|}{ Coronary Artery Disease } \\
\hline No & & 1 & ref \\
\hline Yes & $0.35(1)$ & $\begin{array}{l}1.26(0.58- \\
2.74)\end{array}$ & 0.553 \\
\hline \multicolumn{4}{|l|}{ Cerebrovascular Accident } \\
\hline No & & 1 & ref \\
\hline Yes & $0.16(1)$ & $\begin{array}{l}1.30(0.36- \\
4.61)\end{array}$ & 0.690 \\
\hline \multicolumn{4}{|l|}{ BMI $\left(\mathrm{kg} / \mathrm{m}^{2}\right)$} \\
\hline Normal $(\geq 18.5$ to $<23)$ & & 1 & ref \\
\hline Overweight $(\geq 23$ to $<27.5$ ) & $3.07(1)$ & $\begin{array}{l}0.26(0.06 \\
-1.17)\end{array}$ & $0.080 *$ \\
\hline Obesity ( $\geq 27.5$ ) & $2.63(1)$ & $\begin{array}{l}0.29(0.07- \\
1.30)\end{array}$ & $0.105^{*}$ \\
\hline \multicolumn{4}{|l|}{ Waist circumference } \\
\hline Normal $(\mathrm{WC}<90 \mathrm{~cm})$ & & 1 & ref \\
\hline
\end{tabular}

${ }^{*} P$-value $<0.25$ is statistically significant. 


\begin{tabular}{|c|c|c|c|}
\hline Variable & $\begin{array}{l}\text { Wald } \\
\text { (df) }\end{array}$ & $\begin{array}{l}\text { Crude OR } \\
(95 \% \mathrm{Cl})\end{array}$ & $P$-value \\
\hline Abnormal $(\mathrm{WC} \geq 90 \mathrm{~cm})$ & $0.12(1)$ & $\begin{array}{l}1.10(0.64- \\
1.87)\end{array}$ & 0.731 \\
\hline \multicolumn{4}{|l|}{ SBP } \\
\hline Normal (SBP < 140 mmHg) & & 1 & ref \\
\hline Abnormal (SBP $\geq 140 \mathrm{mmHg}$ ) & $5.83(1)$ & $\begin{array}{l}2.00 \\
(1.14- \\
3.51)\end{array}$ & $0.016 *$ \\
\hline \multicolumn{4}{|l|}{ DBP } \\
\hline Normal (DBP < 90mmHg) & & 1 & Ref \\
\hline Abnormal (DBP $\geq 90 \mathrm{mmHg})$ & $3.63(1)$ & $\begin{array}{l}0.52(0.26- \\
1.02)\end{array}$ & $0.057^{*}$ \\
\hline \multicolumn{4}{|l|}{ FBS } \\
\hline Normal (FBS < 7.0 mmol/L) & & 1 & ref \\
\hline Abnormal (FBS $\geq 7.0 \mathrm{mmol} / \mathrm{L}$ & $0.01(1)$ & $\begin{array}{l}1.03(0.56- \\
1.88)\end{array}$ & 0.921 \\
\hline \multicolumn{4}{|l|}{$\mathrm{HbA1c}(n=167)$} \\
\hline Normal (HbA1c< 6.5 mmol/L) & & 1 & ref \\
\hline Abnormal (HbA1c $\geq 6.5 \mathrm{mmol} / \mathrm{L})$ & $0.30(1)$ & $\begin{array}{l}0.79(0.35- \\
1.82)\end{array}$ & 0.585 \\
\hline \multicolumn{4}{|l|}{ Total cholesterol } \\
\hline Normal (Total cholesterol <5.2 mmol/L) & & 1 & ref \\
\hline Abnormal (Total cholesterol $\geq 5.2 \mathrm{mmol} / \mathrm{L}$ ) & $11.14(1)$ & $\begin{array}{l}0.37(0.21- \\
0.67)\end{array}$ & $<0.001^{*}$ \\
\hline \multicolumn{4}{|l|}{ Triglyceride } \\
\hline Normal (Triglyceride $\leq 1.7$ mmol/L) & & 1 & ref \\
\hline Abnormal (Triglyceride >1.7 mmol/L) & $4.36(1)$ & $\begin{array}{l}0.55(0.37- \\
0.97)\end{array}$ & $0.037^{*}$ \\
\hline \multicolumn{4}{|l|}{ LDL (mmol/L) based on CV risk } \\
\hline $\begin{array}{l}\text { Normal (Very High Risk: } \mathrm{LDL}<1.8 \mathrm{mmol} / \mathrm{L} \text {, High Risk: } \mathrm{LDL} \leq 2.6 \\
\mathrm{mmol} / \mathrm{L} \text {, Moderate risk, and Low risk } \mathrm{LDL}<3 \mathrm{mmol} / \mathrm{L})\end{array}$ & & 1 & ref \\
\hline $\begin{array}{l}\text { Abnormal (Very High Risk: LDL } \geq 1.8 \mathrm{mmol} / \mathrm{L} \text {, High Risk: } \mathrm{LDL}< \\
2.6 \mathrm{mmol} / \mathrm{L} \text {, Moderate risk, and Low risk LDL } \geq 3 \mathrm{mmol} / \mathrm{L} \text { ) }\end{array}$ & $2.35(1)$ & $\begin{array}{l}0.66(0.39- \\
1.12)\end{array}$ & $0.125^{\star}$ \\
\hline
\end{tabular}




\begin{tabular}{|c|c|c|c|}
\hline Variable & $\begin{array}{l}\text { Wald } \\
\text { (df) }\end{array}$ & $\begin{array}{l}\text { Crude OR } \\
\text { (95\% Cl) }\end{array}$ & $P$-value \\
\hline \multicolumn{4}{|l|}{ HDL } \\
\hline Normal (HDL > $1.0 \mathrm{mmol} / \mathrm{L})$ & & 1 & ref \\
\hline Abnormal (HDL $\leq 1.0 \mathrm{mmol} / \mathrm{L})$ & $3.90(1)$ & $\begin{array}{l}0.56(0.31- \\
1.00)\end{array}$ & $0.048 *$ \\
\hline \multicolumn{4}{|l|}{ Hand Grip Strength centile (kg) } \\
\hline$\geq 25$ th to $<50$ th & & 1 & ref \\
\hline$\geq 10$ to $<25$ th & $1.15(1)$ & $\begin{array}{l}0.64(0.28- \\
1.45)\end{array}$ & 0.283 \\
\hline$<10$ th & $33.90(1)$ & $\begin{array}{l}16.49 \\
(6.42- \\
42.36)\end{array}$ & $<0.001$ \\
\hline
\end{tabular}

A multivariate (stepwise) binary logistic regression analysis was undertaken to assess the relationship between the sociodemographic characteristics and comorbid predictors and ED. The model consisted of 13 independent variables: elderly, education level, income classification, smoking status, hypertension, obesity, elevated systolic blood pressure and diastolic blood pressure, total cholesterol, triglyceride, and HGS. Following the stepwise regression, the full model containing the three remaining factors was statistically significant as shown in Table 4. The model explained the variance of ED between 31\% (Cox and Snell $\mathrm{R}^{2}$ ) and $48.8 \%$ (Nagelkerke $\mathrm{R}^{2}$ ), as well as correctly classified $88.6 \%$ of cases. There independent factors were identified; elderly factor, HGS $<10$ th centile and total cholesterol. 
Table 4

Factors associated with ED among men with Metabolic Syndrome from multiple logistic regression

Variable

\begin{tabular}{llll|} 
Crude OR $^{\mathrm{a}}$ & Adjusted OR $^{\mathrm{b}}$ & $\begin{array}{l}\text { Wald statistic }^{\mathrm{b}} \\
(\mathrm{df})\end{array}$ & $\begin{array}{l}\mathrm{P} \\
\text { value }^{\mathrm{b}}\end{array}$ \\
\cline { 1 - 2 }$(95 \% \mathrm{Cl})$ & $(95 \% \mathrm{Cl})$ & & \\
\hline
\end{tabular}

\section{Age Group}

Young $(\geq 40$ to $<60)$

1

1

Elderly $(\geq 60)$

$4.26(2.36-$

7.70)

$3.27(1.60-$

6.69)

$10.52(1)$

0.001

\section{Total Cholesterol}

Normal (Total cholesterol $<5.2$

$\mathrm{mmol} / \mathrm{L}$ )

$\begin{array}{llll}\text { Abnormal (Total cholesterol } \geq 5.2 & \begin{array}{l}0.374(0.21- \\ \mathrm{mmol} / \mathrm{L})\end{array} & 0.67) & 0.36(0.16- \\ 0.78) & 6.68(1) & 0.010\end{array}$

\section{Hand Grip Strength centile}

$\geq 25$ th to $<50$ th

1

1

$<10$ th

16.49 (6.42-

42.36)

$15.35(5.64-$

41.81)

28.54(1)

$<0.001$

$\geq 10$ to $<25$ th

$0.64(0.28-$

1.45)

0.57 (0.23-

1.39)

$1.54(1)$

0.215

${ }^{\text {a }}$ Simple logistic regression ${ }^{b}$ Multiple logistic regression

The Hosmer- Lemeshow goodness-of-fit test showed the final model was fit $(p=0.915)$ and area under ROC curve (88.6\%). There were no interaction or multicollinearity.

\section{Discussion}

\section{Prevalence of ED}

A majority of men among MetS had ED in our study. Our result was consistent with a study in Egypt, which reported that the prevalence of ED was $79.4 \%$ in men aged between $30-75$ years old who had MetS (37). Previous studies also shown similar prevalence as in this study with more than $70 \%$ of men with MetS had ED $(38,39)$. The prevalence of ED among MetS were not surprising to be higher compared to the general populations in Asian, and Western studies (1, 3, 5, 40-43). This study supports the strong pathogenicity of MetS in ED $(39,44)$. The relationship between MetS and ED was first described by Gunduz et al. in 2004 (45) and there were consistent findings in the literature which reported that MetS was strongly associated with ED $(38,39,46-48)$. A meta-analysis revealed that patients with MetS had 2.6-fold increased risk of having ED (48). 
The reason for this is generally attributed to a constellation of interrelated cardiac risk factors consisting of insulin resistance, abdominal obesity, atherogenic dyslipidemia, and systemic inflammation that can cause ED (49). MetS can result in endothelial dysfunction, which has been implicated in atherosclerosis leading to ED. In a study conducted by Thompson et al., a strong association was indicated between elevated biomarkers of inflammation and endothelial dysfunction with increased odds of prediabetes, diabetes, and MetS among adults in China (49). Endothelial dysfunction leads to a decrease in vascular nitric oxide levels, that results in impaired vasodilation and the increase in free radical concentration also leads to atherosclerotic damage (49).

\section{HGS and ED}

Our study supports the inverse relation between HGS and risk of developing ED. We found lower HGS centile had a higher risk of ED, with HGS of < 10th centile has risk of ED more than 15-folds. HGS is a simple, convenient, and inexpensive measurement method to assess overall strength of an individual apart from being a potential indicator of health conditions (21). HGS refers to the greatest force or tension exerted by the hand and forearm muscles using a dynamometer. Measurement of HGS can be used to assess overall strength as its well correlated with muscle strength measurement from arm, trunk, and leg. HGS can be influenced by age, gender, body mass index, hand dominance, smoking status, alcohol consumption and nutritional status (27).

This measure is traditionally used to diagnose hand function after hand injury and used in rehabilitations in setting treatment goals to evaluate the outcome of hand surgery (28). Low HGS was associated with higher risk of overall morbidity and mortality, longer hospital stay and poor physical function (50). Poor HGS also reflects frailty which are mainly attributed by presence of comorbidities such as CVD, diabetes, and dyslipidemia - all of which are linked to quality of lifestyle and $\operatorname{ED}(16,20,51)$. The association of HGS with ED was reported by Chung et al., who revealed that greater hand strength had lower risk of moderate to severe ED with OR $0.82,95 \% \mathrm{Cl} 0.74-0.90$ (24) and Kumagai et al reported that with 1 kilogram of handgrip increment, the IIEF5 will improve by $16 \%$ (25). Nevertheless, Park et al. (2020), found that HGS was not significantly associated with severe ED with OR $0.76,95 \% ; \mathrm{Cl}, 0.30$ to $1.91(52)$, which should be confirmed in future studies.

The biological mechanism linking HGS, and ED is still controversial. Lower HGS indicates muscle weakness or reduced muscle function. It was believed that reduced muscle function may cause reduction in muscle contraction. During muscle contraction, myocyte will synthesize inducing factors such as myokine. This myokines has anti-inflammatory effects that induce metabolic actions that are associated with the prevention of CVD $(53,54)$. This assumption of low HGS strength will have reduction of myokine that will cause chronic inflammatory scenario that contributes to an imbalance in endothelial dysfunction, which leads to CVD and ED. Furthermore, high muscular strength signifies high muscular mass in which consisting of skeletal, cardiac and smooth muscles. The skeletal muscle, also known as the primary protein site, accounts for $85 \%$ of glucose metabolism via the adiponectin receptors (55). Adiponectin is a protein hormone and adipokine that regulates fatty acid metabolism and glucose levels. 
The interaction of this adiponectin with its receptor could have antihyperglycemic, anti-atherogenic, and anti-inflammatory effects, potentially slowing the progression of CVD (55).

It was discovered that positive effect of muscular strength and muscle mass include maintenance or increase in resting metabolic rate; the prevention of age-associated fat gains; the reduction of visceral adipose tissue; improvements in blood glucose levels, basal insulin levels, insulin response, and insulin sensitivity; improvements in resting blood pressure, and decreases in $\mathrm{HbA1c}$ in diabetics patient (56). This modifiable risk factors also link to ED, and which subsequently will improve ED.

\section{ED and other associated factors}

This study supports elderly aged 60 years old and above is an independent factor for ED which further confirms that the prevalence of ED is rising with advancing age $(1-3,40,57)$. The concomitant presence of co-morbid illnesses and increase use of medications as aging occurs are plausible causes. With advancing age, the physiological changes of atherosclerosis in blood vessels may compromise the blood flow to the penile organs and thus increasing the risk of ED. Another possible explanation is that the aging process decreases the functions of various organs, including the skeletal muscle which is known as sarcopenia. Sarcopenia can be associated with low testosterone level due to the decrease of anabolism of the skeletal muscle. Sarcopenia was associated with severe ED with OR $1.89,(95 \% \mathrm{Cl} 0.18$ to 3.03 ) among elderly men in Korea (52).

Abnormal total cholesterol was shown to have a decreased risk with OR $0.374,95 \% \mathrm{Cl} 0.21-0.67$. This finding is unexpected and is contrary to the findings in most literatures $(58,59)$. It is difficult to explain this result, but it may be related to the participants of this study, whom a majority had dyslipidemia; thus, they may be prescribed with common anti-lowering cholesterol drugs such as statin. Therefore, it is possible that statin can reduce the risk of ED as reported by a few meta-analyses (60-63). Unfortunately, information about statin was not collected in this study. Besides, more than half participants who had abnormal total cholesterol were of younger age groups.

Many literatures reported the strong relationship between diabetes, cardiovascular diseases, and ED (9, $64,65)$. However, our findings did not support the association of diabetes, presence of CVD and ED. Recent studies in Nepal and India showed a longer duration of DM and poor glycaemic control with $\mathrm{Hba} 1 \mathrm{C} \geq 7 \%$ had higher risk of $\operatorname{ED}(64,65)$. Nisahan et al also found that duration of DM, and presence of microvascular complications were associated with ED (66). However, few studies also did not found an association of glycaemic control with $\operatorname{ED}(66,67)$ which correspond with our study. Thus, serial HbA1c levels over time could be a useful tool in assessing long-term glycaemic control, with a better correlation than a single $\mathrm{HbA} 1 \mathrm{C}$ value. Our inconsistency findings may be due to the limited information on the duration of diabetes and presence of diabetes complications that predict ED.

Endothelial dysfunction has been linked to both CVD and ED, and it plays a significant role in the progression of atherosclerosis. However, our study did not show the association of CVD and ED like other studies $(2,66)$. This may be due to our study participants who were on beta blocker and diuretic were 
excluded. Our study participants also had better control of CVD risk factors such as blood pressure and lipid control.

\section{Clinical Implication and Recommendations}

The current study discovered that ED was very common in men with MetS. The presence of ED to predict atherosclerotic involvement of coronary arteries within 2 to 5 years, emphasises the importance of ED screening among men above 40 years of age with MetS. ED is a critical men's health issue that must be included in all risk-screening programmes in primary care settings for early identification of risk factors and early cardiology intervention. In addition, raising public awareness about the importance of early detection of ED, particularly among men with metabolic syndrome should be done.

Our study found that lower HGS had higher risk of ED and as a result, HGS could be used to identify people who are at risk of developing ED and that increasing muscle strength might be a possible intervention for ED. Focused muscle strengthening exercise or resistance training intervention may improve outcome, but further study is needed to investigate effectiveness of resistance training in improving ED. Furthermore, future research directed to develop resistance training exercise prescription for men at risk of ED may be beneficial for clinicians and fitness professionals. Nevertheless, pharmacotherapy is the most effective treatment for ED in short term, but muscle strengthening exercises may be necessary for improvement of ED.

\section{Strength and Limitations}

To the best of our knowledge, this is the first study to find the association between HGS and ED among men with MetS. The used of probability sampling also reduced sampling bias. However, there were several limitations. The participants were predominantly of Malay race. We also had limited information regarding diabetes duration and its complications that may contribute to ED. Findings of this study may not be generalisable to other primary care clinics in other settings.

\section{Conclusion}

In conclusion, most men aged above 40 years with MetS had ED. HGS, elderly and abnormal total cholesterol were associated with ED. A lower HGS predicted higher risk of ED, suggesting that reduced muscle strength may contribute to ED. Further studies are needed to determine whether handgrip strength can be used for evaluation of ED risk among men with Mets and suggesting possible intervention of using resistance training for maintaining muscle mass and strength to improve ED.

\section{Abbreviations}

BP: blood pressure

BMI: body mass index

Cl: confidence interval 
CVD: cardiovascular diseases

DBP: diastolic blood pressure

ED: erectile dysfunction

EMR: electronic medical record

FPG: fasting plasma glucose

FSL: fasting serum lipid

HDL-C: high density lipoprotein - cholesterol

HGS: hand-grip strength

IIEF-5: International Index of Erectile Function- 5

IQR: interquartile ranges

JIS: Joint Interim Statement

LDL-C: low density lipoprotein - cholesterol

MetS: metabolic syndrome

MLogR: multiple logistic regression

OR: Odds ratio

RM: Ringgit Malaysia

ROC: receiver operating characteristic

RT: resistance training

SBP: systolic blood pressure

SD: standard deviation

SLogR: simple logistic regression

SPSS: statistical package for Social Sciences

TG: triglycerides

WC: waist circumference 


\section{Declarations}

\section{Ethical Consideration}

This study was approved by the local ethics committee from the Research Ethics Committee of Universiti Teknologi MARA (600-TNCPI (5/1/6), REC/01/2021 (FB/03)) in compliance with the Declaration of Helsinki and the code of ethics of the World Medical Association. All participants were informed regarding the purpose of the study, their rights, and confidentiality. Written informed consent were obtained from the participants before they enrolled in the study.

\section{Consent for publication}

The consent of the participant for publication is inapplicable because the participant's individual data was not described in the manuscript.

\section{Availability of data and materials}

The corresponding author will share data upon request, and it is subjected to data protection regulations. The data are available and preserved at the Primary Care Medicine Department, Universiti Teknologi MARA (UiTM), Selayang Campus, Jalan Prima Selayang 7, 68100 Batu Caves, Selangor, Malaysia.

\section{Competing interests}

None.

\section{Funding}

This study was not subsidized by any grant.

\section{Author's contribution}

Each author has contributed sufficiently to the work to accept public responsibility for appropriate portions of the described contents. NANAK and SAR wrote the manuscript. NANAK was involved in the data collection. AMD performed the statistical analysis and contributed to the critical discussion of the results. NMN contributed to the critical revision of the manuscript. All authors read and approved the final manuscript.

\section{Acknowledgment}

We would like to thank Dr Lim Teck Onn, for permitting us to use the IIEF-5 Malay version. We would also like to extend our appreciation to the participants and staff of Faculty of Medicine, Universiti Teknologi MARA for their contributions during data collection.

\section{References}


1. Quilter $M$, Hodges $L$, von Hurst P, Borman B, Coad J. Male sexual function in New Zealand: a population-based cross-sectional survey of the prevalence of erectile dysfunction in men aged 40-70 Years. J Sex Med. 2017;14(7):928-36.

2. Oyelade BO, Jemilohun AC, Aderibigbe SA. Prevalence of erectile dysfunction and possible risk factors among men of South-Western Nigeria: a population based study. Pan Afr Med J. 2016;24:124.

3. Zhang X, Yang B, Li N, Li H. Prevalence and risk factors for erectile dysfunction in Chinese adult males. J Sex Med. 2017;14(10):1201-8.

4. Korneyev IA, Alexeeva TA, Al-Shukri SH, Bernikov AN, Erkovich AA, Kamalov AA, et al. Prevalence and risk factors for erectile dysfunction and lower urinary tract symptoms in Russian federation men: analysis from a national population-based multicenter study. Int J Impot Res. 2016;28(2):74-9.

5. Ab Rahman AA, Al-Sadat N, Yun Low W. Prevalence of erectile dysfunction in primary care setting, Malaysia. Journal of Men's Health. 2011;8(S1):S50-S3.

6. Fadzil MA, Sidi H, Ismail Z, Hassan MR, Thuzar K, Midin M, et al. Socio-demographic and psychosocial correlates of erectile dysfunction among hypertensive patients. Compr Psychiatry. 2014;55 Suppl 1:S23-8.

7. De Rocco Ponce M, Vecchiato M, Neunhaeuserer D, Battista F, Caretta N, Savalla F, et al. Association between penile color doppler ultrasonography and cardiorespiratory fitness in patients with vascular erectile dysfunction. Sex Med. 2021;9(3):100347.

8. Sanchez E, Pastuszak AW, Khera M. Erectile dysfunction, Metabolic Syndrome, and cardiovascular risks: facts and controversies. Transl Androl Urol. 2017;6(1):28-36.

9. Diaconu CC, Manea M, Marcu DR, Socea B, Spinu AD, Bratu OG. The erectile dysfunction as a marker of cardiovascular disease: a review. Acta Cardiol. 2020;75(4):286-92.

10. Ciumărnean L, Milaciu MV, Negrean V, Orășan OH, Vesa SC, Sălăgean O, et al. Cardiovascular risk factors and physical activity for the prevention of cardiovascular diseases in the elderly. Int $\mathrm{J}$ Environ Res Public Health. 2021;19(1).

11. Tikkanen E, Gustafsson S, Ingelsson E. Associations of fitness, physical activity, strength, and genetic risk with cardiovascular disease. Circulation. 2018;137(24):2583-91.

12. Gerbild H, Larsen CM, Graugaard C, Areskoug Josefsson K. Physical activity to improve erectile function: a systematic review of intervention studies. Sex Med. 2018;6(2):75-89.

13. Elagizi A, Kachur S, Carbone S, Lavie CJ, Blair SN. A review of obesity, physical activity, and cardiovascular disease. Current Obesity Reports. 2020;9(4):571-81.

14. Giuliano C, Karahalios A, Neil C, Allen J, Levinger I. The effects of resistance training on muscle strength, quality of life and aerobic capacity in patients with chronic heart failure - a meta-analysis. Int J Cardiol. 2017;227:413-23.

15. Lee L, Patel T, Costa A, Bryce E, Hillier LM, Slonim K, et al. Screening for frailty in primary care: accuracy of gait speed and hand-grip strength. Can Fam Physician. 2017;63(1):e51-e7. 
16. Leong DP, Teo KK, Rangarajan S, Lopez-Jaramillo P, Avezum A, Jr., Orlandini A, et al. Prognostic value of grip strength: findings from the Prospective Urban Rural Epidemiology (PURE) study. Lancet. 2015;386(9990):266-73.

17. Shim J, Yoo HJ. Effects of handgrip strength on 10-year cardiovascular risk among the Korean middle-aged population: the Korea national health and nutrition examination survey 2014. Healthcare (Basel). 2020;8(4):458.

18. Ruiz JR, Castro-Piñero J, Artero EG, Ortega FB, Sjöström M, Suni J, et al. Predictive validity of healthrelated fitness in youth: a systematic review. Br J Sports Med. 2009;43(12):909-23.

19. Riebe D, Ehrman, J. K., Liguori, G., \& Magal, M.. American college of sport medicine's guidelines for exercise testing and prescription. 14th ed.: Philadelphia: Lippincott Williams \& Wilkins; 2014.

20. Beyer SE, Sanghvi MM, Aung N, Hosking A, Cooper JA, Paiva JM, et al. Prospective association between handgrip strength and cardiac structure and function in UK adults. PloS one. 2018;13(3):e0193124-e.

21. McGrath R, Johnson N, Klawitter L, Mahoney S, Trautman K, Carlson C, et al. What are the association patterns between handgrip strength and adverse health conditions? A topical review. SAGE Open Med. 2020;8:2050312120910358-.

22. Lee SH, Gong HS. Measurement and interpretation of handgrip strength for research on sarcopenia and osteoporosis. J Bone Metab. 2020;27(2):85-96.

23. Mgbemena NC, Aweto HA, Tella BA, Emeto TI, Malau-Aduli BS. Prediction of lung function using handgrip strength in healthy young adults. Physiol Rep. 2019;7(1):e13960-e.

24. Chung HS, Shin MH, Park K. Association between hand-grip strength and erectile dysfunction in older men. Aging Male. 2018;21(4):225-30.

25. Kumagai H, Yoshikawa T, Myoenzono K, Kosaki K, Akazawa N, Tanahashi K, et al. Role of high physical fitness in deterioration of male sexual function in Japanese adult men. Am J Mens Health. 2019;13(3):1557988319849171.

26. Dodds RM, Syddall HE, Cooper R, Benzeval M, Deary IJ, Dennison EM, et al. Grip strength across the life course: normative data from twelve British studies. PLOS ONE. 2014;9(12):e113637.

27. Manoharan V, Sundaram S, Jason I. Factors affecting hand grip strength and its evaluation: a systemic review. International Journal of Physiotherapy and Research. 2015;3:1288-93.

28. Kim CR, Jeon Y-J, Jeong T. Risk factors associated with low handgrip strength in the older Korean population. PloS one. 2019;14(3):e0214612-e.

29. Department of Statistics Malaysia Official Website-Current population estimates, Malaysia. 2020. Available online: https://www.dosm.gov.my. Accessed 30 December 2021.

30. Alberti KG, Eckel RH, Grundy SM, Zimmet PZ, Cleeman JI, Donato KA, et al. Harmonizing the Metabolic Syndrome. Circulation. 2009;120(16):1640-5.

31. Leong DP, Teo KK, Rangarajan S, Kutty VR, Lanas F, Hui C, et al. Reference ranges of handgrip strength from 125,462 healthy adults in 21 countries: a Prospective Urban Rural Epidemiologic 
(PURE) study. Journal of Cachexia, Sarcopenia and Muscle. 2016;7(5):535-46.

32. Lim T, Das A, Rampal S, Zaki M, Sahabudin R, Rohan M, et al. Cross-cultural adaptation and validation of the English version of the International Index of Erectile Function (IIEF) for use in Malaysia. International journal of impotence research. 2003;15:329-36.

33. Department of Statistics Malaysia Official Website-Household Income and Basic Amenities Survey Report. 2019. Available online: https://www.dosm.gov.my. Accessed 30 December 2021.

34. Mutalip MH, Kamarudin RB, Manickam M, Abd Hamid HA, Saari RB. Alcohol consumption and risky drinking patterns in Malaysia: findings from NHMS 2011. Alcohol Alcohol. 2014;49(5):593-9.

35. Malaysian Health Technology Assessment Section. Clinical practise guideline on management of dyslipidemia. 5th ed. Putrajaya: Ministry of health; 2017. p. 180 p.

36. Malaysian Health Technology Assessment Section. Clinical practise guideline on management of obesity.1st ed. Putrajaya: Ministry of health; 2004. p. 58 p.

37. Salama MN, Eid AA, Hatem A, Swidan AK. Prevalence of erectile dysfunction in Egyptian males with Metabolic Syndrome. The Aging Male. 2020;23(4):257-63.

38. Demir T, Demir O, Kefi A, Comlekci A, Yesil S, Esen A. Prevalence of erectile dysfunction in patients with Metabolic Syndrome. Int J Urol. 2006;13(4):385-8.

39. Bal K, Oder M, Sahin AS, Karataş CT, Demir O, Can E, et al. Prevalence of Metabolic Syndrome and its association with erectile dysfunction among urologic patients: metabolic backgrounds of erectile dysfunction. Urology. 2007;69(2):356-60.

40. Braun M, Wassmer G, Klotz T, Reifenrath B, Mathers M, Engelmann U. Epidemiology of erectile dysfunction: results of the 'Cologne Male Survey'. Int J Impot Res. 2000;12(6):305-11.

41. Martins FG, Abdo CHN. Erectile dysfunction and correlated factors in Brazilian men aged 18-40 years. J Sex Med. 2010;7(6):2166-73.

42. Morillo LE, Díaz J, Estevez E, Costa A, Méndez H, Dávila H, et al. Prevalence of erectile dysfunction in Colombia, Ecuador, and Venezuela: a population-based study (DENSA). Int J Impot Res. 2002;14 Suppl 2:S10-8.

43. Cheng JY, Ng EM, Ko JS, Chen RY. Physical activity and erectile dysfunction: meta-analysis of population-based studies. Int J Impot Res. 2007;19(3):245-52.

44. Maiorino MI, Bellastella G, Giugliano D, Esposito K. From inflammation to sexual dysfunctions: a journey through diabetes, obesity, and Metabolic Syndrome. Journal of Endocrinological Investigation. 2018;41(11):1249-58.

45. Gündüz MI, Gümüs BH, Sekuri C. Relationship between Metabolic Syndrome and erectile dysfunction. Asian J Androl. 2004;6(4):355-8.

46. Lee YC, Liu CC, Huang CN, Li WM, Wu WJ, Yeh HC, et al. The potential impact of Metabolic Syndrome on erectile dysfunction in aging Taiwanese males. J Sex Med. 2010;7(9):3127-34.

47. Gorgel SN, Gorgel A, Sefik E. Sexual function in male patients with Metabolic Syndrome and effective parameters on erectile dysfunction. International braz j urol. 2014;40:56-61. 
48. Besiroglu H, Otunctemur A, Ozbek E. The relationship between Metabolic Syndrome, its components, and erectile dysfunction: a systematic review and a meta-analysis of observational studies. J Sex Med. 2015;12(6):1309-18.

49. Thompson-Paul A, Zhang Y, Tong W, Xu T, Chen J, Zhao L, et al. Association of inflammation and endothelial dysfunction with metabolic syndrome, prediabetes and diabetes in adults from Inner Mongolia, China. BMC Endocr Disord. 2011;11:16.

50. McGrath RP, Kraemer WJ, Snih SA, Peterson MD. Handgrip strength and health in aging adults. Sports Medicine. 2018;48(9):1993-2000.

51. Liu W, Leong DP, Hu B, AhTse L, Rangarajan S, Wang Y, et al. The association of grip strength with cardiovascular diseases and all-cause mortality in people with hypertension: findings from the prospective urban rural epidemiology China study. Journal of Sport and Health Science. 2021;10(6):629-36.

52. Park $H$, Jang IY, Han M, Lee $H$, Jung HW, Lee E, et al. Sarcopenia is associated with severe erectile dysfunction in older adults: a population-based cohort study. Korean J Intern Med. 2020;35(5):124553.

53. Barbalho SM, Flato UAP, Tofano RJ, Goulart RdA, Guiguer EL, Detregiachi CRP, et al. Physical exercise and myokines: relationships with sarcopenia and cardiovascular complications. Int J Mol Sci. 2020;21(10):3607.

54. Barbalho SM, Prado Neto EV, De Alvares Goulart R, Bechara MD, Baisi Chagas EF, Audi M, et al. Myokines: a descriptive review. J Sports Med Phys Fitness. 2020;60(12):1583-90.

55. Lee M-R, Jung SM, Kim HS, Kim YB. Association of muscle strength with cardiovascular risk in Korean adults: findings from the Korea National Health and Nutrition Examination Survey (KNHANES) VI to VII (2014-2016). Medicine. 2018;97(47).

56. Carbone S, Kirkman DL, Garten RS, Rodriguez-Miguelez P, Artero EG, Lee D-c, et al. Muscular strength and cardiovascular disease: an updated state-of- the-art narrative review. Journal of Cardiopulmonary Rehabilitation and Prevention. 2020;40(5).

57. Saeed R, Amin F, Durrani N, Saif SMA, Zafar MT. Prevalence of erectile dysfunction and associated factors among males visiting family medicine clinics in a tertiary care hospital in Karachi, Pakistan. J Family Med Prim Care. 2021;10(3):1294-300.

58. Nikoobakht M, Nasseh H, Pourkasmaee $M$. The relationship between lipid profile and erectile dysfunction. International Journal of Impotence Research. 2005;17(6):523-6.

59. Li M, Ma Z, Zhang X-L, Guo L-Q, Yuan M-Z. Significance of blood lipid parameters as effective markers for arteriogenic erectile dysfunction. Andrology. 2020;8(5):1086-94.

60. Cai X, Tian Y, Wu T, Cao C-X, Bu S-Y, Wang K-J. The role of statins in erectile dysfunction: a systematic review and meta-analysis. Asian J Androl. 2014;16(3):461-6.

61. Cui $Y$, Zong $H$, Yan $H$, Zhang Y. The effect of statins on erectile dysfunction: a systematic review and meta-analysis. The Journal of Sexual Medicine. 2014;11(6):1367-75. 
62. Chou CY, Yang YF, Chou YJ, Hu HY, Huang N. Statin use and incident erectile dysfunction- a nationwide propensity-matched cohort study in Taiwan. Int J Cardiol. 2016;202:883-8.

63. Elgendy AY, Elgendy IY, Mahmoud AN, Al-Ani M, Moussa M, Mahmoud A, et al. Statin use in men and new onset of erectile dysfunction: a systematic review and meta-analysis. Am J Med. 2018;131(4):387-94.

64. Tamrakar D, Bhatt DS, Sharma VK, Poudyal AK, Yadav BK. Association between erectile dysfunction and type 2 diabetes mellitus. J Nepal Health Res Counc. 2021;19(2):378-83.

65. Nutalapati S, Ghagane SC, Nerli RB, Jali MV, Dixit NS. Association of erectile dysfunction and type II diabetes mellitus at a tertiary care centre of south India. Diabetes \& Metabolic Syndrome: Clinical Research \& Reviews. 2020;14(4):649-53.

66. Nisahan B, Kumanan T, Rajeshkannan N, Peranantharajah T, Aravinthan M. Erectile dysfunction and associated factors among men with diabetes mellitus from a tertiary diabetic center in Northern Sri Lanka. BMC research notes. 2019;12(1):210.

67. Feldman HA, Goldstein I, Hatzichristou DG, Krane RJ, McKinlay JB. Impotence and its medical and psychosocial correlates: results of the Massachusetts male aging study. J Urol. 1994;151(1):54-61.

\section{Figures}


A list of all male patients who had follow-up at the primary care clinic from $1 / 1 / 2020$ until $31 / 12 / 2020$ was obtained from the IT unit. $(\mathbf{n}=\mathbf{3 4 7 1})$.

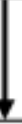

All male patients with metabolic syndrome were identified and numbered from 1 until 2200. $(\mathbf{n}=\mathbf{2 2 0 0})$.

All male patients who had metabolic syndrome were randomly sampled using a computer-generated random sampling number to achieve the sample size. (n=444) (https://stattrek.com/statistics/random-number-generator .aspx).

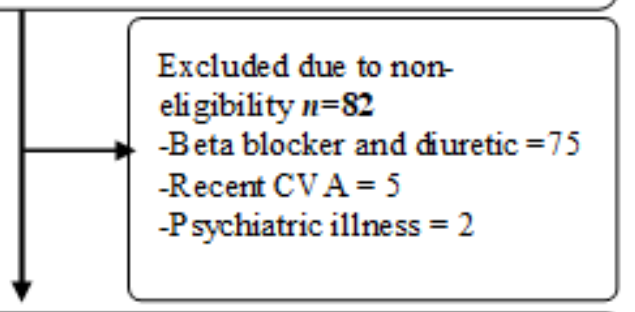

All selected subjects were called to confirm their presence for their follow -up.

\section{Figure 1}

The flowchart of the study 